\title{
Urdimento
}

Revista de Estudos em Artes Cênicas E-ISSN: 2358.6958

\section{Correspondências flutuantes: O butoh na voz das mulheres em Abya Yala}

Sandra Corradini Simone Mello

\section{Para citar este artigo:}

CORRADINI, Sandra; MELLO, Simone.

Correspondências flutuantes: o butoh na voz das mulheres em Abya Yala. Urdimento, Florianópolis, v. 3, n. 39, nov./dez. 2020.

DOI: http:/dx.doi.org/10.5965/14145731033920200213

Este artigo passou pelo Plagiarism Detection Software | iThenticate 
Correspondências flutuantes: o butoh na voz das mulheres em Abya Yala

Sandra Corradini

Simone Mello²

\begin{abstract}
Resumo
Este trabalho parte de correspondências eletrônicas trocadas com as dançarinas de butoh Eugenia Vargas (México) e Susana Reyes (Equador) em meio à crise pandêmica do coronavírus no mundo. Inquietações compartilhadas com as artistas buscaram fomentar autorreflexões acerca de suas práticas no butoh, que são aqui analisadas a partir de um entrelaçamento teórico inscrito no trânsito Abya Yala-Japão. A abordagem persegue pistas que permitem organizar um conjunto de ideias acerca das qualidades e das potências do corpo, trabalhadas por ambas, e refleti-lo como uma possível hipótese evidenciada pela troca de cartas. Os achados corroboram o corpo como um lugar expressivo, íntimo e gerador de mitopoéticas, vistas como dança pessoal, experimentadas e tecidas a partir de relações com suas próprias culturas e ancestralidades em face da informação estrangeira.
\end{abstract}

Palavras-chave: Butoh. Dança pessoal. Mitopoética feminina. Memória. Coronavírus.

Floating correspondences: the butoh and women's voice in Abya Yala

\begin{abstract}
This article expands on the electronics correspondences exchanged with the butoh dancers Eugenia Vargas (Mexico) and Susana Reyes (Ecuador) in the midst of the worldwide coronavirus pandemic crisis. Concerns shared with the artists sought to foment self-reflections about their practices in the butoh, which are analyzed here from a theoretical interweaving inscribed in the Abya Yala-Japan transit. The approach pursues clues that allow organizing a set of ideas about the qualities and powers of the body, worked on by both, and reflecting it as a possible hypothesis evidenced by the exchange of letters. The findings corroborate the body as an expressive, intimate and mythopoetic generating place, seen as personal dance, experienced and woven from relationships that the artists establish with their own culture and ancestry in the face of foreign information.
\end{abstract}

Keywords: Butoh. Personal dance. Female mythopoetic. Memory. Coronavirus.

${ }^{1}$ Doutoranda e mestre em Dança pela Universidade Federal da Bahia, bacharel em Dança pela Unicamp. Fisioterapeuta residente no Programa Multiprofissional em Neurologia, em Salvador/BA. Artista e colaboradora do Núcleo Cuerpo Fluctuante (Brasil-Peru). sandracorradini@gmail.com

2 Mestre em Dança e pós-graduada (especialização) em Estudos Contemporâneos de Corpo pela Universidade Federal da Bahia, Licenciada em Dança pela Universidade Paulista de Artes. Bailarina e fundadora do Núcleo Cuerpo Fluctuante (Brasil-Peru). cuerpofluctuante@gmail.com 
Correspondencia flotante: el butoh en la voz de las mujeres en Abya Yala

\section{Resumen}

Este trabajo se basa en el intercambio de correspondencia electrónica con las bailarinas de butoh Eugenia Vargas (México) y Susana Reyes (Ecuador) en medio de la crisis pandémica del coronavirus en el mundo. Las inquietudes compartidas con los artistas buscaron fomentar la autorreflexión sobre sus prácticas en el butoh, que aquí se analizan a partir de un entrelazado teórico inscrito en el tránsito Abya YalaJapón. El enfoque persigue pistas que permitan organizar un conjunto de ideas sobre las cualidades y poderes del cuerpo, trabajadas por ambos, y reflejarlo como una posible hipótesis evidenciada por el intercambio de cartas. Los hallazgos corroboran el cuerpo como lugar expresivo, íntimo y generador de mitopoéticas, visto como una danza personal, vivida y tejida a partir de relaciones con su propia cultura y ascendencia frente a informaciones ajenas.

Palabras clave: Butoh. Baile personal. Mitopoética femenina. Memoria. Coronavirus. 


\section{Correspondências para repensar o butoh em tempos de mudanças}

O presente trabalho desdobra-se como um ato reflexivo expandido de um projeto cartográfico em curso (Passos; Kastrup; Tedesco, 2014), desenvolvido pelo Núcleo de Pesquisa Cuerpo Fluctuante, que teve início com o isolamento social, decorrente da crise do coronavírus no mundo, mais especificamente, em março do corrente ano. O impacto da pandemia nas atividades de muitos artistas, que tiveram seus projetos paralisados e sem perspectiva de retorno à "normalidade", promoveu um fenômeno distópico de crise na arte, desencadeado pela reclusão domiciliar e consequente busca por novas formas de produzir arte, impondo o desafio de sobreviver e de se adaptar a esta nova realidade. As inquietações das autoras acerca do butoh na América Latina acentuaram-se neste momento pandêmico e confluíram na formalização do referido projeto, que propõe interlocução, por meio de troca de cartas, por correspondência eletrônica, com mulheres que atuam com butoh na América Latina.

O panorama geral das correspondências abrange indagações acerca do butoh na América Latina, procurando instaurar e/ou fomentar um processo reflexivo nas artistas colaboradoras acerca de seus próprios trabalhos, sem pretender obter respostas prontas. Ressalta-se que o fluxo conversacional empreendido nas trocas de cartas não se fez com base em perguntas e respostas, consistindo mais em estímulos para uma escuta dialógica, interessada no fluir livre e criativo das ideias na configuração das reflexões relatadas pelas dançarinas acerca de suas experiências individuais.

Se de fato o butoh vem conquistando uma voz própria em Abya Yala, o que poderia sinalizar esta vocalização? Em que medida um possível desorientalismo poderia fomentar o processo de edificação de uma voz própria do butoh como forma de arte possível em nossas terras? Podemos considerar as mulheres coautoras nesta construção? Quais ensinamentos advindos de vivências vinculadas à prática do butoh

\footnotetext{
O Cuerpo Fluctuante é um núcleo de pesquisa artístico-acadêmica que desenvolve projetos com a colaboração de artistas de diferentes países latino-americanos. Através de encontros presenciais e virtuais, realiza processos artísticos e pedagógicos baseados na investigação do corpo que dança butoh, buscando mover-se na América Latina e, assim, promover arte, cultura, experiência e produção de conhecimento.
} 
podem ajudar no trânsito dos corpos durante esta crise viral que assola toda humanidade e de maneira corrosiva a vida dos artistas? (Corradini; Mello, 2020).

Esta escrita rizomática envereda-se por pressupostos que ajudam a pensar a aproximação do butoh no Japão do pós-guerra ao butoh das mulheres na América Latina em tempos atuais de pandemia do coronavírus no mundo, e pensamentos formulados por duas artistas, colaboradoras neste projeto do núcleo. Ambas são dançarinas, coreógrafas e produtoras-gestoras de festivais de butoh, reconhecidas como expoentes e impulsoras do butoh em seus respectivos países e na América Latina: Eugenia Vargas, mexicana, fundadora e diretora do Laboratorio Escénico Danza Teatro Ritual', e Susana Reyes, equatoriana, fundadora e diretora do Danza Butoh de los Andes 5 . Mais que apresentar suas visões pessoais do butoh que praticam ou propor uma possível tradução de suas formas poéticas de tratar o butoh em palavras, a proposta é caminhar por reflexões acerca de suas próprias experiências artísticas e levantar um conjunto de ideias acerca das qualidades e das potências do corpo dançarino, trabalhadas por ambas, e refleti-lo como uma possível hipótese evidenciada pela troca de cartas.

Entre o Japão, de Tatsumi Hijikata, e o butoh em Abya Yala

Abya Yala é o termo que vem sendo utilizado como uma autodesignação dos povos originários do continente em contraponto ao uso do termo América como forma de transpor a generalização eurocêntrica de povos indígenas e gerar um sentimento de unidade e de pertencimento. Esta expressão foi usada pela primeira vez em 1507, reaparecendo em 2004, em evento ${ }^{6}$ dos povos indígenas da América Latina, realizado em Quito, com intenção de brindar um sentido mais político e

\footnotetext{
Empresa que se concentra na produção, difusão e promoção da dança butoh no México e com a qual organiza Cuerpos en Revuelta - Festival Internacional de Butoh Dance na América Latina.

Empresa que desde 1985 mantém junto com o músico Moti Deren, desenvolvendo um vasto repertório artístico com o qual viaja por Equador e vários países, mediante oficinas itinerantes e uma plataforma especial para mulheres.

6 Evento // Cumbre Continental de los Pueblos y Nacionalidades Indígenas. Para mais informações: http://www.cumbreindigenabyayala.org/
} 
original do termo, que, na língua do povo Kuna (Panamá), significa Terra madura, Terra Viva, Terra em florescimento (Porto-Gonçalves, 2015a).

Ailton Krenak, um dos maiores líderes do movimento indígena brasileiro, cujos nome e povo significam cabeça da terra, é tido como uma das grandes vozes promotoras da Abya Yala. Ele, que traz no nome as memórias de seus antepassados e a grande mãe Terra como morada de origem, lugar coletivo e habitat da humanidade, contribui para desorientalizar esta escrita ao se referir a Abya Yala como território afetivo, possivelmente imaginado, e que demarca uma posição de afirmação e de resistência à pressão da colonização contínua sofrida pelos povos originários desde a "descoberta do novo continente". Mais que um alerta, sua fala é um ato reivindicatório:

Que papo é esse de América Latina? Ora nada mais é que um produto colonial - chamar este continente de América é a rendição absoluta continuar chamando nossa terra de América que diz respeito a Vespúcio - o veneziano que passou por aqui - descobrindo a rota para os exploradores, é homenagear o assalto! (Krenak apud Gitti, 2020).

Abya Yala é território comum habitado por diferentes culturas, etnias, memórias e costumes, que há muito o caracterizam e lhe conferem diversidade e complexidade. O uso do termo no presente trabalho vem ao encontro de uma visão mais engajada, política e crítica ao processo de empoderamento decolonial, permitindo, ainda, dilatar o espaço-tempo, alargar a percepção e conectar com outras complexidades e realidades criadas em outras redes e em outros contextos histórico-culturais, engendradas por diferentes enlaces conectivos.

Para Eugenia Vargas (2020), dançarina mexicana, tudo começa com um leve bater de asas de uma borboleta; um bater ligeiro, que, como diz o antigo provérbio chinês, pode ser sentido do outro lado do mundo. Para ela, nesta crise global, o bater de asas levou à instabilidade no sistema de produção capitalista e à parada das atividades na classe artística, o que, apesar de fugir às regras da cadeia produtiva, pode ser visto como uma pausa, uma oportunidade para refletir, calar, voltar para casa e à casa mais íntima, que é o próprio corpo. 
Suas palavras trazem pistas de uma dança que passeia por lugares imaginados, praticada a partir de uma compreensão abrangente de mundo, a qual inclui México, Brasil, Equador e Japão, hemisférios norte e sul, oriente e ocidente, tudo em um espaço único. Faz-se notar seu olhar para a inter-relação entre eventos remotos, os impactos e efeitos que geram entre si e suas reverberações para além do próprio evento. Suas palavras evidenciam um pensar-agir em dança transpassado por um filtro poético embebido em saberes ancestrais, denotando uma lógica que opera entre corpo, dança e cultura, em uma rede particular de conexões.

En mi imaginación, esta conversación ocurre en un jardín, a la sombra de una gran jacaranda que, de vez en vez, deja caer su flor morada sobre nuestras cabelleras, evocando no sólo la llegada de una estación sino el florecimiento de un movimiento indómito que exige el respeto inalienable de los derechos de las mujeres, e integro en este clamor, los derechos de nuestra madre, la Pachamama: vasija sagrada que nos sostiene y alimenta. (Vargas, 2020).

O avanço no exercício reflexivo das práticas de butoh das mulheres em Ayba Yala pressupõe pensar o deslocamento do dualismo entre oriente e ocidente para entendê-los como um continuum, para além da linha criada pela geografia imaginativa, que se estendeu e se estende por milhares de anos de domínio europeu no mundo, dividindo a grande massa continental entre Europa, poderosa e articulada, e Ásia, derrotada e distante (Said, 1990, p. 67). Mais que a simples divisão geográfica, o orientalismo separa e confronta culturas, raças, crenças, valores e religiões, e cria um corpo de teorias e de práticas com um investimento material vultoso, gerando um sistema de conhecimento aceitável sobre o oriente, que filtra o oriente para a consciência ocidental. (Said, 1990, p. 18).

Cabe destacar que embora Ayba Yala e Oriente sejam termos que apresentem em comum a abrangência de amplos territórios, eles não compartilham sentidos iguais ou semelhantes. Abya Yala configura-se como parte de um processo de construção político-identitário de descolonização do pensamento, enquanto oriente diz respeito ao caráter marginal-periférico à Europa (Porto-Gonçalves, 2015b), advindo de um processo de colonização da Ásia e do 
Oriente Médio pelas nações europeias, iniciado no final do século XVIII. Frequentemente, o oriente referido pelos americanos diz respeito ao extremo oriente, em especial, à China e ao Japão (Said, 1990). Neste trabalho, enfoca-se o Japão; mais precisamente, o Japão de Tatsumi Hijikata, coreógrafo e dançarino japonês que viveu exclusivamente no Japão entre os anos de 1928 a 1986 e pensou sua dança como resposta à colonização ocidental em seu país. Trata-se de um Japão delimitado por espaços geográfico e imaginários relativos a um tempo histórico-cultural específico, que abrange desde Akita, sua terra natal, a Tóquio, incluindo Tohuku, região nordeste de Honshu, principal ilha do Japão, em um Japão de reconstrução econômica e cultural após sua derrota e destruição na Segunda Guerra Mundial.

Hijikata repensou radicalmente a dança em seu país, subvertendo valores e padrões éticos e estéticos de um Japão tradicional e conservador ao mesmo tempo em que transgrediu convenções de modernidade impostos pela sua nova condição de Japão americanizado e europeizado. Transformou e deformou componentes teatrais do tradicional teatro No e, sobretudo, do Kabuki (Peretta, 2015), antagonizando em cena elementos técnicos e dramatúrgicos propagados pelo balé clássico e pelas danças modernas americana e europeia, que já avançavam no Japão desde o início do século XX. Ao romper com tais pensamentos estéticoartísticos, estabeleceu um diálogo intercultural profícuo com elementos de seu tempo e de sua cultura, deixando-se contaminar por outras linguagens, como cinema, literatura, artes plásticas e música, delineando uma nova forma de dança híbrida, marginal, experimental e revolucionária, chamada Ankoku Butoh, cuja poética portava uma força tensional e desviante, sustentada por elementos que posteriormente nortearam as bases para o desenvolvimento do butoh no Japão, tendo como cofundador o coreógrafo e dançarino Kazuo Ohno.

Ankoku Butoh é fruto do projeto Ankoku Kabuki, nascido nos anos 1960 entre as paisagens concretas e mnemônicas de Akita, em Tohoku, lugar onde Hijikata viveu sua infância e adolescência. Trata-se de um projeto que revelou um consistente posicionamento político-ideológico, no qual a escuridão e as práticas culturais de Tohoku ganharam uma nova dimensão estético-artística, ancorada na 
existência humana. Com base em suas experiências de vida, Hijikata pensou a escuridão como forma de tornar visível o invisível, a partir das suas lembranças da escuridão em Tohoku, que the permitia ver a luz das estrelas e aguçava-lhe os sentidos e a sutil percepção das coisas. As matrizes poéticas de sua dança transcenderam o corpo japonês do pós-guerra, permitindo a investigação do corpo em suas dimensões psíquicas e fisiológicas, pautada na subversão do corpo cultural por meio da exploração de diferentes qualidades do corpo que compunham a materialidade crua do organismo humano, ou seja, o corpo de carne. (Peretta, 2015, p.152).

Hijikata tornou-se uma espécie de símbolo dos corpos que definham, dedicando sua vida a confrontar as crises que habitam o corpo (Vieira, 2007; Greiner, 2010). Empenhou-se na investigação do corpo morto, liberto dos automatismos e das ordenações sociais, fazendo da degradação das formas corpóreas sua constante busca. Sua estratégia era colapsar categorias internas do corpo por meio de um jogo de tensões, no qual os contrastes engendravam a ação, partindo de ações simples e cotidianas (Greiner, 2005). Explorou o corpo enfraquecido em seus espaços íntimos e em situações não habituais e ficcionais, concebendo-o em sua identidade fluida como corpo aberto, inacabado, afirmando sua condição de existência com base na realidade concreta e material.

A complexidade de seus pensamentos chegou ao Brasil e à Argentina juntamente com o Butoh nos anos 1990 e pouco a pouco adentrou outros países vizinhos, construindo um terreno fértil e novos caminhos para reinvenção das fabulações poéticas do corpo que dança. Desde então, o butoh parece manter-se como uma forma de expressão enigmática, capaz de mobilizar pessoas, paixões e estudos em direções distintas e pouco previsíveis. De acordo com Greiner (2013, p. 7), "em cada cultura por onde o butoh transita, ele terá um significado diferente e modos específicos de testar a arte, o corpo e os limiares entre a vida e a morte".

A dança de Hijikata parece ativar potências nos corpos das mulheres que buscam seguir dançando em tempos atuais de pandemia em Abya Yala. É certo que o contexto atual não é mais o do pós-guerra, período em que explodiu o movimento butoh no Japão, surgindo como uma resposta artística radical aos discursos pré- 
fabricados e importados. Do mesmo modo, o embate, hoje, já não é mais o das tradições milenares japonesas com os novos valores ocidentais impostos à sociedade japonesa, que desencadeou a crise cultural e a configuração do butoh no Japão. Nem todas as perguntas sobre o que Hijikata realmente disse e fez, e quais foram, de fato, seus pensamentos podem ser respondidas. Porém, suas palavras expressam claramente sua linha de combate contra o sistema capitalista e as instituições políticas que docilizam o corpo como modo de manter, controlar e retroalimentar positivamente o próprio sistema.

Todo o poder da moral civilizada, de mãos dadas com o sistema econômico capitalista e suas instituições políticas, está profundamente oposto ao uso do corpo simplesmente para o objetivo, meio ou ferramenta do prazer. Ainda mais, para uma sociedade orientada à produção, o uso desapropriado do corpo, ao qual eu chamo dança, é um inimigo mortal que precisa ser tabu. Eu sou capaz de dizer que minha dança compartilha uma base comum com o crime, a homossexualidade masculina, os festivais e rituais porque são comportamentos que explicitamente ostentam seu despropósito na face de uma sociedade orientada produtivamente. Neste sentido, minha dança baseada na autoativação humana, incluindo a homossexualidade masculina, o crime e uma batalha naife com a natureza, pode naturalmente ser um protesto contra a 'alienação do trabalho' na sociedade capitalista. Esta é também, provavelmente, a razão porque expressamente aproximei-me dos marginais. (Hijikata, 2000, p. 44-45).

Hijikata permite olhar para a dança como um campo favorável para desorientalizar, repensar o corpo butoh em Abya Yala e penetrar em uma nova reinvenção dos corpos no presente momento pandêmico. Tornar próximo o distante, abrir portas e deixar que os saberes do oriente habitem nossas casas, nossos corpos, sobrepor mapas e criar um espaço que permita atravessamentos, tornar o estranho familiar, o exótico habitual, o absente presente, o excepcional comum, o extraordinário frequente, e desvencilhar dos supostos imaginários que nutrem fetiches, exotismos, estereótipos, clichês abstratos e herméticos, experiências melodramáticas, etc., como Greiner (2013) sugere pensar, em seus estudos acerca do(s) butô(s) na América Latina.

Parece importante manter uma certa toxicidade que garante a vitalidade das experiências no sentido de desestabilizar o anestesiamento que nos 
assola, expondo as invisibilidades e as fragilidades do corpo, na contramão dos holofotes que privilegiam a assepsia fictícia da vida. (Greiner, 2013, p. 7).

Edward Said, por sua vez, sugere orientar o olhar pelas lentes através das quais o butoh e o Japão de Hijikata são experimentados, pois são elas que moldam a linguagem, a percepção e a forma do encontro entre o butoh em Ayba Yala e o butoh de Hijikata no Japão. Said (1990, p. 68) explica que "o que confere alguma unidade ao imenso número de encontros é a vacilação entre o familiar e o estrangeiro. Algo claramente estrangeiro e distante, por uma ou outra razão, tornase mais, e não menos, familiar".

\section{O butoh na voz das mulheres em Abya Yala}

Por un lado creo que el butoh latino-americano ha logrado su propia voz y por otro lado creo que es maravilloso y necesario que rescates ese hecho tan particular que ha sido la presencia de las mujeres en esta construcción de un butoh latino-americano. (Reyes, 2020).

A presença das mulheres no processo de construção do butoh em Abya Yala parece irrevogável. Há um lugar de autoria importante reservado às mulheres que atuam na construção dos saberes do corpo que nutrem o butoh há tempos em terras novas, sobretudo, desde a vinda de Kazuo Ohno no Brasil e na Argentina, em 1986, para apresentação de seu solo La Argentina Sho (Admirando La Argentina), dirigido por Hijikata, em 1977. Como ressaltado por pesquisadores, trata-se de um momento de expansão internacional do butoh que se deu a partir da apresentação deste solo no $14^{\circ}$ Festival de Teatro de Nancy, na França, em 1980. (Yokoyama, 2018; Peretta, 2015).

Mais que um corpo de homem e vestido de mulher, Ohno, neste solo, traz uma "beleza invertida" aos padrões estéticos de beleza, preconizados em seu contexto artístico. Na figura de Ohno, o butoh materializou no corpo elementos da urbanidade, da sexualidade e do humor, associados à atmosfera subversiva oriunda das manifestações populares, em especial, o Yose, teatro de massa do final do 
século XIX, ancestral do Kabuki (Peretta, 2015, p. 42). Nota-se, aqui, a presença da androgenia como uma síntese de perversidade e de erotismo, cuja ênfase se dá na “mistura dos papéis sexuais para marcar a desordem social” (Katz, 1994), tratandose de questão estética concernente ao butoh, mas também à cultura tradicional japonesa, a qual cultua até hoje um padrão de beleza em que não se distingue os sexos. No entanto, a valorização da androgenia no butoh, com ênfase na caracterização feminina do corpo masculino, ainda pode ser vista como uma insubordinação às interdições governamentais na arte Kabuki sofridas por séculos, que impediram a participação das mulheres na cena, que passaram a ter seus papeis encenados exclusivamente por homens, modificando radicalmente sua forma inicial, encenada somente por mulheres. Como explica Handa (2020), por ter uma ênfase no sensual e no sensacional, o teatro Kabuki trazia na plateia o olhar dos homens que enfocavam a beleza feminina apenas em sua plasticidade corporal em detrimento da obra encenada, de modo que as mulheres foram impedidas de atuar, mantendo-se as formas exageradas e estilizadas como eixo central, associadas ao grotesco e ao sobre-humano, ao longo de um processo de adaptação e de renovação constante do teatro kabuki na cultura japonesa.

Tais aspectos parecem ser importantes para se pensar o butoh das mulheres em Abya Yala ao olhar para as reflexões trazidas nas cartas de Eugênia Vargas. Para esta dançarina mexicana (2020), a dança, de modo geral, é reconhecida como área ligada ao gênero feminino. Vargas nota um desprezo geral pela arte por parte da sociedade, por sua improdutividade em termos mercadológicos. Observa, contudo, um desprezo ainda maior pela dança, por nela estar implícito o uso do corpo, o qual se aprende a silenciar desde a mais tenra infância. Neste contexto, é possível perceber a existência de uma visão restrita acerca dos processos na dança em Abya Yala, a qual tende apartá-los dos processos sociais, bem como cindir a unidade corpomente e valorizar a mecanização do gesto e a objetificação da mulher. Tratase, pois, de um fenômeno sócio-político-econômico que reclama o butoh como um movimento de resistência e de contracultura para questionar e negar as normas e dos padrões culturais dominantes. 
As reflexões de Vargas acerca de sua dança adquirem consonância com as ideias de Katz (1994) acerca do butoh, fazendo-se notar um modo de pensar a dança que rejeita a superficialidade das coisas, tendo o inconsciente e o mundo interior como alvos e a transformação como condição de acesso à dança como um modo de existência. Vargas acredita que a dança permite ao dançarino enraizar-se à profundidade de seu corpo, sendo, ao longo da história, uma maneira natural, íntima e poderosa de expressão que lança o corpo no jogo dionisíaco da vida, intoxicandoo com seu transe comemorativo. Como explica, os dançarinos de butoh são "equilibristas dançando em uma corda bamba sobre o abismo. (Vargas, 2020).

Vargas desenvolve uma dança que dialoga com o butoh, referindo-se a ela como dança pessoal. Para ela, o butoh exige a entrega honesta e desnuda do dançarino, que precisa se lançar à sua própria experiência sem pretensão e juízo, e sem se vangloriar da pira dionisíaca, sendo aí, neste lugar, que a dança verdadeiramente acontece, como arrebatamento, transe, entusiasmo de ser, de estar sendo, de ser movido, de ser dançado. Vargas considera que a transformação ontológica fundamental no butoh, a qual é possível somente quando desaparece a identidade social. A dançarina afirma que é neste momento que o dançarino se converte em canal: “Junco vacío por donde el viento canta” (Vargas, 2020).

As palavras de Vargas fluem em movimentos que transitam entre México e Japão, deixando o pensamento às voltas com paisagens flutuantes que soam como metáforas de espaços criados em sua imaginação. Enquanto reflete aspectos importantes de sua dança à sombra dos jacarandás, que de vez em vez deixam uma flor cair como pedra sobre cabeças vez ou outra desavisadas, Reyes, não menos engajada, coloca-se na direção de uma prática, mergulhando em um espaço íntimo, buscando alcançar a imensidão.

Para Susana Reyes (2020), o butoh é mais que uma meta, é uma porta que a leva a si mesmo, a sua unicidade; uma porta que a permite entrar em sua alma, criar, sarar e renascer dia a dia. Seu encontro com o butoh the trouxe uma sensação de reaproximação com algo antigo que já the pertencia. Reyes refere-se a este encontro como um sincronismo cósmico, reconhecendo sua dança praticada como forma de cura, associada à espiritualidade. 
Importa destacar, aqui, a perspectiva bifurcada que tomou o butoh em relação à dimensão espiritual, fazendo-se notar distinções conceituais, contrastadas nas práticas corporais de Ohno e de Hijikata, dadas pelos seus diferentes modos de pensar as relações entre forma e conteúdo e, antes disso, entre poética e religião, mobilizadas pelas dissonâncias entre o pensamento cristão de Ohno e o ateísmo de Hijikata.

\begin{abstract}
A questão da improvisação, bem como a relação entre forma e o "espírito" na dança, delineia uma cisão basilar na obra de ambos os artistas. Ohno considerava a dança como uma arte da improvisação, coerentemente com a concepção de que a sua forma se concretizaria por si mesma, desde que existisse um conteúdo espiritual que a convocasse. Hijikata, por sua vez, possuía uma concepção mais metódica e precisa da dança. [...] refutava explicitamente a improvisação como procedimento técnico na cena, mesmo que a assumisse como recurso, por vezes catártico, em seus processos de construção cênica. Para ele, baseado em seu radical materialismo, a vida é que perseguiria a "forma", isto é, a precisão do gesto de um dançarino, uma vez transmutado - quase em um nível quântico em objeto, "convocaria" o seu espírito a energia que animaria a sua expressividade passiva. (Peretta, 2015, p. 155-156).
\end{abstract}

Reyes parece desenvolver sua relação com o butoh como um exercício diário, uma prática de si para transformação de sua existência, fundada em processos de subjetivação para acesso a verdade; o acesso à verdade, visto como acesso ao próprio ser, sendo ele mesmo agente de transformação de si (Foucault, 2006, p. 236). Depois de anos debruçada em estudos da tradição japonesa, Reyes acredita ter encontrado a convergência entre os princípios do butoh e sua cultura andina, investindo no entendimento do corpo como memória. Para Reyes (2019): "En la cultura andina se habla del cuerpo como un cofre contenedor de la historia de la humanidad, de la memoria total, individual, colectiva, planetaria, de la naturaleza. También el butoh busca el origen, los impulsos primarios".

Reyes criou o espetáculo Memorias de Arcilla7 (2002) inaugurando uma pesquisa denominada Dança Butoh dos Andes. Com uma trajetória de mais de vinte anos na dança, almeja alcançar aspectos da cultura primitiva e reconectar céu e terra com um fio sagrado, lugar onde diz estar sentada neste instante-agora. Ao

7 In: http://www.artezblai.com/artezblai/se-estrena-en-quito-memorias-de-arcilla-de-susana-reyes.html 
enredar sua dança a sua cultura andina, Reyes desenha, assim como Vargas, reflexões acerca de sua dança pessoal, não somente expandida de um contexto individual, mas situada em um campo ampliado do corpo, ramificado na humanidade (Fuganti, 2007). Mais especificamente, um corpo com memórias que atravessam o espaço, o tempo e o próprio corpo em devir permanente e ativo, conectado a um espaço íntimo que enxerga sua catexia impulsiva como força mobilizadora dos processos primários do corpo, vinculados ao inconsciente. (Sadock; Ruiz, 2017, p. 155).

Vargas, por sua vez, também oferece pistas de sua dança pessoal ao reiterar a ancestralidade dos povos originários de México, a qual habita seu corpo como fonte primária de investigação. Ao constatar este traço comum entre vargas e Reyes, observa-se que ambas assumem para si a nomenclatura de dança pessoal para a dança que praticam. Para ambas, o corpo é visto sob uma perspectiva ampliada, que se deixa afetar pelos saberes ancestrais perpetuados na história e que se move e dialoga com as coisas que existem, relacionando-se com elas em um lugar íntimo, onde encontra sua força geradora.

La danza, en estas tierras, de donde también emergen nuestros cuerpos y nuestra cultura, tiene la dicha de reconocer lo sagrado que habita en todo. Tenemos la herencia ancestral de una cultura extraordinaria que habla con el viento, con el fuego, con el agua, con la tierra, que se asombra ante lo maravilloso, que se conmueve con lo diminuto, así como con lo inmenso, que se rinde ante lo sagrado y lo cultiva. En ese sentido, el bagaje cultural que vive en el rumor de nuestra sangre es el alimento de nuestra danza, nutrida con la potencia de la tierra y con el eco de los pasos de todas las abuelas y abuelos que nos han precedido, que han sabido escuchar y hablar con las estrellas, con las piedras, con los animales, con las flores y eso antiguo que llevamos dentro, es nuestra fuerza. (Vargas, 2020).

Ao enlaçar as palavras dessas duas artistas, seus discursos e produção dos saberes, dissolvem-se as fronteiras e borram-se as autorias, construindo-se novas subjetividades na dança e para além deste campo artístico e do conhecimento. De mesmo modo é o butoh de Hijikata, de Kazuo Ohno e de seus discípulos, que ao ganhar o mundo e espalhar sementes para fora do Japão, conquistou o domínio 
público e colidiu em novos platôs de compreensão e de atuação, constituindo uma nova identidade, dotada de múltiplas presenças e de visões práticas e conceituais.

É preciso olhar para o butoh como um movimento em contínuo processo de reconstrução. Butoh não é sinônimo de corpos tortos, músculos tensos, movimentos lentos, corpos pintados de branco, reprodução nos corpos de imagens dos corpos de mestres de butoh ou de seus expoentes máximos e criadores Tatsumi Hijikata e Kazuo Ohno. Como movimento, o butoh se renova cotidianamente nas práticas em sala de aula, workshops, pesquisas artísticas e acadêmicas, processos dramatúrgicos, coreografias, cenas, mesas de debate, rodas de conversa, palestras, entrevistas, etc., e também em cartografias e correspondências, como das quais expande esta escrita.

Em terras de Abya Yala, distintos corpos e culturas diversas emergem dotados de herança ancestral e de bagagem cultural singulares, podendo ser vistos como materiais consistentes para elaboração de dramaturgias do corpo, configurando múltiplas danças. O butoh vem ganhando novas tonalidades em Abya Yala, permitindo e estimulando a vivência do corpo que dança como agente na transformação da própria existência e dos processos inseridos em contextos artístico-políticos e histórico-culturais diversos. Se em uma margem distante estão as memórias da escuridão afrontadas por Hijikata, em Abya Yala, estão as trajetórias de mulheres como Vargas e Reyes, que trabalham na militância permanente de novos campos poéticos, nutrindo um solo comum com suas práticas, que ajudam a florescer esta manifestação estrangeira como poesia que alimenta terras novas, fertilizando o corpo que dança com a multiplicidade, onde "o leve bater de asa da borboleta pode ser sentido do outro lado do mundo." (Vargas, 2020).

\section{O butoh das mulheres em Abya Yala perante a experiência do desastre}

Estamos dentro do desastre, ninguém precisa tirar a gente, temos que atravessar o deserto. Experimentem buscar um lugar onde possam se deitar na terra, com a pele do corpo se misturando o que você pensa que é, e assim a terra vai falar com você. (Krenak apud Gitti, 2020). 
Em 1967, depois de uma larga temporada em Tokio, Hijikata retornou a Tohoku, sua terra natal, região conhecida como o lado escuro do Japão. Motivado pelo desejo de reavaliar seu processo na dança e de promover uma espécie de renascimento, mergulhou nas raízes de sua comunidade camponesa e nas lembranças de sua infância assolada pela guerra. Neste período de isolamento, buscou aprofundar sua pesquisa, desenvolvendo os princípios que nortearam a construção de seu legado. Maura Baiocchi (1995, p. 9) explica que "mais que a um simples retorno às fontes, procedeu a uma fértil busca do reconhecimento do elo ancestral". Imerso nas paisagens de Akita, Hijikata iniciou um processo de resgate de suas memórias de infância, esboçando os princípios metodológicos do Ankoku Butoh, que semanticamente pode ser interpretado como luz subtraída. Começou a elaborar uma espécie de esboço de sua existência corporal, buscando encarnar em sua dança tudo que experimentou ao longo de sua vida por meio das lembranças. Nesta fase, Hijikata costumava dizer que sua irmã habitava seu corpo, dando início a um processo de sexualidade mutante e passando a utilizar uma linguagem corporal feminina, vestindo-se com kimonos e deixando crescer seu cabelo. Passou a ressignificar seu corpo, colocando-o no centro de uma poética pessoal rumo à "intimidade com as coisas que continuam a morrer as suas próprias mortes" (Hijikata apud Peretta, 2015, p. 79). É desta etapa o último trabalho de Hijikata, que contou com a participação de sua principal discípula Yoko Ashikawa e de um grupo de jovens dançarinos, por ele chamado Tohokukabuki Project (1985). Hijikata redirecionou sua pesquisa, aproximando sua dança ao teatro popular tradicional, buscando novos sentidos na ancestralidade, na terra natal e no feminino (Rocha, 2018, p. 116). Frequentemente, dizia que Tohoku é um país estrangeiro, afirmando em que "apesar de ser Tohoku kabuki, existe um Tohoku na Inglaterra".

Hijikata explorou exaustivamente a dialética entre o local e o universal, o feminino e o masculino, o tradicional e a vanguarda. Seus discípulos foram conduzidos a confrontar seus corpos com a desintegração do humano, formulando o butoh como um campo de investigação infinita, que não se restringe somente as mazelas dos corpos japoneses. Yoko Ashikawa, expoente feminina do butoh, acredita que o corpo butoh pode se transformar em tudo, "de um tapete 
molhado a um céu e podem até incorporar o universo" (Kurihara apud Nanako, 2000, p. 16). Para ela, não basta apenas usar a imaginação; tem que ser, alterar a condição do próprio corpo.

Neste trabalho, a tarefa é abrir, reabrir e manter vivo o diálogo que visita o corpo cênico, sempre atravessado da tensão entre a captura e a fuga, o engano e o erro, a concentração e a dispersão, atualizando velhas inquietações em novas perguntas. Também é seguir reforçando e renovando premissas flutuantes e perturbadoras, apostando na troca de correspondências como método que permite uma conexão íntima entre corpos situados em espaços distantes. Entende-se que a reclusão dos corpos dançarinos, confinados neste momento de crise pandêmica mundial, pode promover aproximações do corpo com ele mesmo, entre corpos e destes com suas terras e histórias de danças e de vida. Por este viés, e nestes tempos sombrios de pandemia no mundo, reivindica-se a tarefa de manter vivas as pulsações dos movimentos epifânicos do butoh em uma espécie de virtualização do corpo que dança em nossas terras, trabalhando como antídoto de uma ciência nômade, fugidia e transformadora.

Por meio da troca de cartas das autoras com as artistas do México e do Equador, constata-se a importância de manter vivo o butoh como um ato filosófico diário, tornando-o presente nos pequenos gestos cotidianos como uma forma de movimentação engajada na micro e na macroesfera artística e sociopolítica. Este trabalho é uma espécie de retorno do investimento destas duas dançarinas no butoh e em si mesmas, mas, no entanto, não se restringe somente a elas. Por meio de seus relatos e suas danças pessoais, entendidas como mitopoéticas femininas, ambas movimentam culturas, dinamizam e reconstroem memórias, perpetuando e rebelando-se contra estruturas sociais e políticas que exploram seus corpos, crenças e valores. Trata-se de uma força nascida na intimidade de seus corpos, que se expande e redesenha mapas, borra fronteiras, aproxima extremos e costura saberes e histórias; estes que, por sua vez, produzem e fazem circular conhecimentos em dança, arte e cultura. O butoh, ao se tornar parte das pesquisas destas artistas, passa a mover-se em Abya Yala, engendrado por singularidades femininas, aptas a reconhecerem e a cultivarem um lugar íntimo, que se fortalece 
como locus de manifestação de mitopoéticas que consagram relações de afeto individuais e coletivas com elementos de suas próprias ancestralidades e culturas.

Os mortos são meus professores. Devemos cuidar bem dos mortos. Mais cedo ou mais tarde também seremos chamados. [...] temos que trazer os mortos para perto de nós e levar nossas vidas com eles. Não há nada a não ser claridade agora. Mas me pergunto se esta claridade não chegou nas costas da escuridão dentro de nós. (Hijikata apud Baiocchi, 1995, p. 33-34).

\section{Referências}

BAIOCCHI, Maura. Butoh: dança veredas d'alma. São Paulo: Palas Athena, 1995.

CORRADINI, Sandra; MELLO, Simone. Correspondência I. [mensagem pessoal]. Mensagem enviada por <cuerpofluctuante@gmail.com.br> 20 abr. 2020.

FOUCAULT, Michel. A hermenêutica do sujeito. São Paulo: Martins Fontes, 2006.

FUGANTI, Luiz. Corpo em devir. Revista Sala Preta, São Paulo, v. 7, p. 67-76, 2007.

GITTI, Gustavo. Ailton Krenak sobre como adiar o fim do mundo. O Lugar: práticas de transformação, 2020. Disponível em: https://olugar.org/ailton-krenak-sobrecomo-adiar-o-fim-do-mundo/. Acesso em: 21 jun. 2020.

GREINER, Christine. Butô(s) na América Latina: uma reflexão crítica. São Paulo: Fundação Japão, 2013.

GREINER, Christine. O corpo em crise: novas pistas e o curto-circuito das representações. São Paulo: Annablume, 2010.

GREINER, Christine. O colapso do corpo a partir do ankoku butô de Hijikata Tatsumi, 2005. Disponivel em:

https://www.japonartesescenicas.org/ankokubutoh.pdf Acesso em: 31 ago. 2020. HANDA, Francisco. Kabuki: uma forma de teatro popular estilizado. In: cultura Japonesa. Disponível em:

http://www.culturajaponesa.com.br/index.php/diversos/teatro/kabuki/ . Acesso em: 31 ago. 2020.

HIJIKATA, Tatsumi. To prison. TDR, TDR - The Drama Review, Cambridge, v. 44, n. 1, Spring, 2000.

KATZ, Helena. Um movimento das entranhas para a pele. O Estado de São Paulo. 19 nov. 1994. Disponível em: 
http://www.helenakatz.pro.br/midia/helenakatz101219757750.jpg. Acesso em: 31 ago. 2020.

NANAKO, Kurihara. Hijikata Tatsumi: As Palavras de Butoh. TDR, v. 44, n. 1, 1988.

PASSOS, Eduardo; KASTRUP, Virgínia; TEDESCO, Silvia. A experiência cartográfica e a abertura de novas pistas. In: PASSOS, Eduardo; KASTRUP, Virgínia; TEDESCO, Silvia. Pistas do método da cartografia: pesquisa-intervenção e produção de subjetividade, vol. 2. Porto Alegre: Sulina, 2014, p. 7-14.

PERETTA, Éden. O soldado nu: origens da dança butô. Perspectiva: São Paulo, 2015.

PORTO-GONÇALVES, Carlos Walter. Abya Yala. Enciclopédia Latino Americana, 2015a. Disponível em: http://latinoamericana.wiki.br/verbetes/a/abya-yala. Acesso em: 21 jun. 2020.

PORTO-GONÇALVES, Carlos Walter. Pela vida, pela dignidade e pelo território: um novo léxico teórico político desde as lutas sociais na América Latina/Abya Yala/Quilombola. Polis, Revista Latino Americana, v. 14, n. 41, $2015 b$.

REYES, Susana. Info de Susana Reyes [mensagem pessoal]. Mensagem recebida por<cuerpofluctuante@gmail.com.br>. 26 maio. 2020.

REYES, Susana. Susana cumple 45 años de labor artística en la danza. La Hora Quito, Quito, 06 mar. 2019. Disponível em:

https://www.lahora.com.ec/cotopaxi/noticia/1102227015/susana-reyes-cumple45-anos-de-labor-artistica-en-la-danza. Acesso em: 21 jun. 2020.

ROCHA, Diego Augusto Pereira da. Butoh: o artesão de si mesmo. Belém, 2018. Dissertação (Mestrado) - Programa de Pós-Graduação em Artes, Instituto de Ciências das Artes, Universidade Federal do Pará, 2018.

SAID, Edward W. Orientalismo: o oriente como invenção do ocidente. São Paulo: Companhia das Letras, 1990.

SADOCK, Benjamim J., SADOCK, Virgínia A., RUIZ, Pedro. Compêndio de psiquiatria: ciência do comportamento e da psiquiatria clínica. 11a ed. Porto Alegre: Artemed, 2017.

VARGAS, Eugenia. Correspondência I [mensagem pessoal]. Mensagem recebida por <cuerpofluctuante@gmail.com.br> 01 maio. 2020.

VIEIRA, Jorge de Albuquerque. Ciência: formas de conhecimento - arte e ciência uma visão a partir da complexidade. Fortaleza: Expansão, 2007. 
YOKOYAMA, Ana Cristina. O campo onde brotou o butoh: antes do filho, o pai. In: Anais do IV Encontro de Pós-Graduandos em Estudos Japoneses, Anais. São Paulo: FFLCH/USP, 2018.

Recebido em: 28/06/2020

Aprovado em: 01/10/2020 